\title{
Uma trama em vários atos. Ou o cinema brasileiro em busca de seu público.
}

\author{
A plot in several acts. \\ Or Brazilian cinema in search of its audience.
}

\section{Uma trama em vários actos. O el cine brasileño em busca de su público.}

\author{
Mannuela Ramos da Costa \\ Universidade Federal de Pernambuco - PE - Brasil \\ ORCID: https://orcid.org/0000-0002-3376-8230 \\ Endereço currículo Plataforma Lattes: http://lattes.cnpq.br/5388593067572622 \\ E-mail: mannuela.costa@ufpe.br \\ William Fernando de Oliveira Santos \\ Universidade Federal de Pernambuco - PE - Brasil \\ ORCID: https://orcid.org/0000-0002-0272-2280 \\ E-mail: william.fernando@ufpe.br
}

\begin{abstract}
Resumo: O presente trabalho objetiva apresentar os resultados da primeira fase da pesquisa de Entre Telas, realizada com consumidores de audiovisual no Brasil, com o objetivo de entender seus hábitos de consumo, como gastos, frequência, suportes e motivações. Para tanto, utilizou-se de pesquisa estruturada, cuja análise se baseia do conceito de habitus e capital cultural (Bourdieu). A pesquisa foi realizada em duas fases, e a primeira, apresentada aqui, colheu respostas através de um questionário online com perguntas de caráter socioeconômico e comportamental referente ao cinema.
\end{abstract}

Palavras-chave: Economia do audiovisual. Cinema brasileiro. Público. Consumo. Hábitos.

\begin{abstract}
This paper aims to present the results of the first phase of the Entre Telas research, carried out with audiovisual consumers in Brazil, in order to understand their consumption habits, such as expenses, frequency, supports and motivations. For that, a structured research was used, whose analysis uses the concept of habitus and cultural capital (Bourdieu). The research was carried out in two phases, and the first, presented here, collected answers through an online questionnaire with socioeconomic and behavioral questions related to cinema.
\end{abstract}

Keywords: Audiovisual economics. Brazilian Cinema. Public. Consumption. Habits. 
Resumén: Este artículo tiene como objetivo presentar los resultados de la primera fase de la investigación Entre Telas, realizada con consumidores audiovisuales en Brasil, con el fin de comprender sus hábitos de consumo, tales como gastos, frecuencia, apoyos y motivaciones. Para ello se utilizó una investigación estructurada, cuyo análisis se basa en el concepto de habitus y capital cultural (Bourdieu). La investigación se llevó a cabo en dos fases, y la primera, aquí presentada, recogió respuestas a través de un cuestionario online con preguntas socioeconómicas y de comportamiento relacionadas con el cine.

Palabras clave: Economía del audiovisual. Cinema brasileño. Público. Consumo. Hábitos.

\section{Introdução}

Ao nos debruçamos sobe as atividades do campo cinematográfico brasileiro percebemos o histórico de instabilidade, marcado por ciclos de altos e baixos, mesclando: fases de crescimento, com reforço institucional, aumento no consumo, euforia na classe e retorno econômico e simbólico; com estagnação, esvaziamento institucional e político, queda na credibilidade e baixo retorno econômico e simbólico. É certo que essa irregular história do cinema no Brasil é fruto de diversos fatores que, conjugados, operam positiva ou negativamente para a sedimentação do campo num determinado período, incluindo aspectos muito pontuais, como a existência de infraestrutura adequada, ou questões de espectro macro-político e econômico mundial (a exemplo das crises econômicas mundiais), além de notadamente estar fortemente influenciado pela instituição do Estado Brasileiro e sua visão sobre o segmento cultural como um todo, do qual o cinema faz parte.

Não é preciso ir muito longe no tempo para esclarecermos a questão. No ano de 1990, quando o governo Collor extinguiu a Embrafilme, empresa estatal que era responsável direta ou indireta por quase toda produção cinematográfica oficial no país, não apenas financiando mas também distribuindo-o e promovendo-o, sem qualquer discussão ou processo administrativo, o país deixou de lançar filmes por 05 anos. Inicia-se assim o período que ficou conhecido como "Retomada", que do ponto de vista político-institucional deriva do conjunto de leis de incentivo federal, mais precisamente a Lei Rouanet $\left(\mathrm{n}^{\mathrm{o}} 8.313 / 91\right)$ e Lei do Audiovisual ( $\mathrm{n}^{\mathrm{o}}$ 8.665/93), e da intervenção e fomento dos governos estaduais e municipais que assumiram o espaço deixado pela Embrafilme. 
Cumulativamente, as discussões entre os representantes do setor e suas entidades representativas não cessou, com discursos que variavam entre as argumentações econômicas e culturais, como bem explica Bahia (2012), concentradas no III CBC (Congresso Brasileiro de Cinema), culminando na criação da Ancine em 2001, pela Medida Provisória 2228-1, de 2001, com o objetivo central de promover o desenvolvimento sustentável do setor. $O$ formato institucional de agência atendia a uma negociação com o setor governamental, que empreendia naquele momento diversas mudanças de ordem econômica e política, para uma redefinição dos limites do Estado.

Os impactos negativos advindos da extinção da Embrafilme explicitaram claramente a importância de uma boa política de estado para o campo cinematográfico. Por isso, a Ancine tinha grandes responsabilidades e foi recebida com grande expectativa pelo setor. Em paralelo, ela encontrou um cenário favorável para desenvolver suas atividades, com as mudanças políticas ocorridas a partir de 2022 no país, que reestruturou todo o aparelho burocrático institucional dedicado à cultura e passou a fomentar de forma contínua e crescente as atividades cinematográficas.

Também se consolidou nesse período o campo de estudos da economia cultural no Brasil, advindo da percepção de que com o conhecimento claro sobre as atividades de um determinado segmento, suas dinâmicas, resultados e impactos das políticas, por exemplo, é possível pensar em ações mais assertivas e que tragam efeitos multiplicadores positivos e duradouros, contribuindo para a efetiva autonomia e sustentabilidade das atividades. Fato é que a própria Ancine começou a sistematizar os dados do mercado, abrangendo as ações de fomento, distribuição, exibição e renda. Analisando esses dados, percebemos que, de uma maneira geral, pode-se afirmar que a política cultural brasileira destinada ao cinema nacional na última década resultou num importante crescimento do setor, que saiu de 71 longas lançados em 2007 para 183 em 2018, de acordo com dados da Ancine ${ }^{1}$. Esse é um crescimento que, como bem descrevem diversos pesquisadores, é muito importante para o desenvolvimento socioeconômico do país, aspecto reforçado. pelos dados seguintes: o audiovisual brasileiro gerou, na economia brasileira, uma renda de $\mathrm{R} \$ 8,7$ bilhões em 2007, e passou a gerar R\$26,7 bilhões, em 2018 (ANCINE).

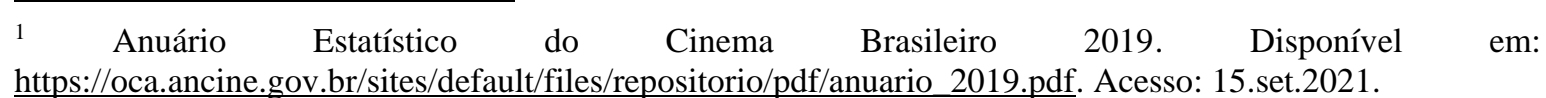


Apesar do aumento da produção ter sido observado com muito entusiasmo nos últimos anos, um dado ainda chama atenção e aponta para uma oportunidade real de crescimento: a pouca penetração do filme brasileiro no mercado interno, que detém cerca de $23 \%$ de participação, em relação ao total de arrecadação nas bilheterias do país, em 2020. Ainda mais considerando as próprias assimetrias da produção interna, pois poucos filmes são responsáveis por grande parte dessa participação. Esse cenário apresenta um problema no sentido de que ao passo em que as políticas públicas de incentivo e fomento aumentam a produção, a fatia do produto nacional se mantém estável, denotando que o público brasileiro ainda não foi fidelizado pelo filme nacional. Portanto, é preciso entender como atuar de forma eficiente nesse setor afim de que haja um aumento também da demanda por esses produtos nacionais, isto é, melhorar a relação com o crescimento da oferta acontecida nos últimos anos (que cresceu não apenas em números, mas em variedade de gêneros e temas). Nesse sentido, temos empreendido pesquisas aplicadas que investigam a performance de um corpus definidos de filmes brasileiros no mercado nacional e internacional, bem como aspectos relativos ao consumidor brasileiro. Distribuição, exibição e consumo são, portanto, os elos da cadeia a que nos dedicamos, por serem evidentes gargalos para o setor cinematográfico brasileiro.

\section{Entre telas: o hábito de consumo audiovisual e os filmes nacionais}

Entendemos que o consumo audiovisual é um hábito, uma prática, que por seu caráter social e cultural, é interpelada por diversas instâncias de ordem estrutural e contextual. Desde aspectos práticos estruturais como recursos financeiros e tempo livre, até a preferência por essa ou outra atividade de lazer e sociabilidade que passa pela mediação dos desejos do indivíduo, organizados dialeticamente em relação aos grupos a que pertence (família, escola, amigos, etc.), bem como pelos discursos de legitimação circulantes (propaganda, crítica especializada, opinião popular, etc.). Nesse sentido, Bourdieu (2007) defende em seus estudos, há uma relação dialética entre o indivíduo, na posição de agente social, e a estrutura social, intermediada pelo que ele chama de habitus. Esse conceito, nas palavras do próprio autor, é o 
[...] sistema das disposições socialmente constituídas que, enquanto estruturas estruturadas e estruturantes, constituem o princípio gerador e unificador do conjunto das práticas e das ideologias características de um grupo de agentes. (BOURDIEU, 2007, p.191)

De forma sintética, podemos dizer que o habitus é uma forma de entender os fatores que levam os indivíduos a agirem de maneira harmoniosa - ou, contrariamente a isso - com o seu grupo ou classe social, ou seja: um intermédio entre as instâncias da estrutura social que legitimam comportamentos e as práticas objetivas do sujeito.

Com essa perspectiva, e já tendo realizado um estudo sobre a performance de filmes pernambucanos lançados entre 2007 e 2016, partimos para uma pesquisa aplicada aos consumidores (ou não) de audiovisual, com base no método de preferência declarada, no que tange às formas, motivações, gastos e outros aspectos, articulado com o perfil sócio-demográfico dos respondentes. Essa seria a primeira fase da pesquisa, a ser complementada por pesquisa de grupo focal, para a testagem de hipóteses e uma análise mais profunda de questões cujas respostas a questionários estruturados ensejam uma racionalização possivelmente maior que aquela efetivamente implicada em situações reais. A ideia é buscar entender o porquê de o cinema brasileiro ter um crescente número de ofertas mas permanecer estagnado em termos de participação de mercado.

A primeira ação consistiu em desenvolver e aplicar um questionário estruturado em perguntas de caráter socioeconômico e comportamental referente aos hábitos de consumo do cinema. $\mathrm{O}$ formulário eletrônico foi disponibilizado através de um link por meio de redes e contatos pessoais, com o cuidado de alcançar públicos fora do circuito de realizadores e pesquisadores da área. Foram 18 questões, sendo 7 dessas sobre o perfil socioeconômico dos respondentes; e 11 sobre hábitos enquanto consumidores e espectadores de cinema. Foram coletadas 168 respostas no período de uma semana, das quais foram excluídas as redundâncias e 158 foram consideradas nessa análise, oriundas de vários estados do Brasil, sendo 75,9\% deles oriundos da região Nordeste.

Os resultados desse questionário nos permitiram observar muitas características importantes sobre o espectador e ainda como a organização estrutural do mercado influencia no hábito de consumo de cinema do público brasileiro (quantidade e diversidade de operadores, tamanho e diversidade da oferta diversidade, bem suas como assimetrias), especialmente em relação a filmes nacionais. Apresentamos, portanto, um 
cruzamento de dados do perfil sócio-demográfico com os hábitos de consumo, tentando elucidar algumas hipóteses que em geral são tomadas como premissas por pesquisadores e profissionais do mercado que atuam na promoção e distribuição de filmes como, por exemplo, relacionar maior renda à maior disposição a gastar em produtos e serviços culturais. Outro aspecto relevante, tanto na concepção de Bourdieu (2007) quanto na análise de público-alvo dos produtos cinematográficos diz respeito às profissões (ou ocupações) e, por conseguinte, a formação educacional instiucional do indivíduo. Após a apresentação e análise dos resultados da amostra para a primeira fase da pesquisa de campo, voltaremos a esse ponto.

\subsection{A renda versus o hábito de ver filmes nacionais}

Uma das principais perguntas sobre comportamento do questionário dizia respeito à frequência com que as pessoas buscam por filmes brasileiros. As respostas se dividiram da seguinte forma:

Gráfico 1 - Gráfico da frequência com que buscam por filmes nacionais.

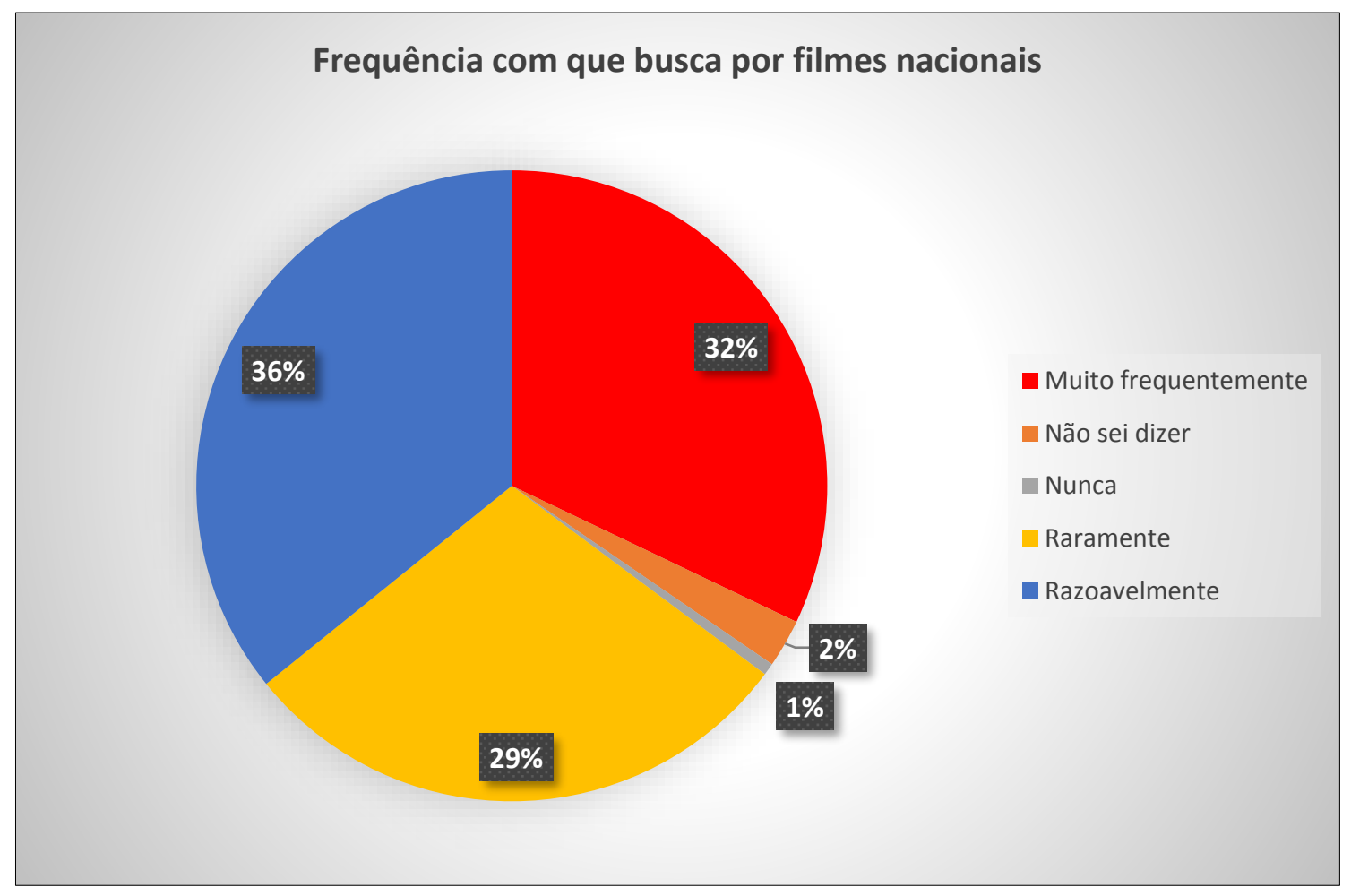

Fonte: Elaboração dos autores. 
Como podemos observar no gráfico da figura 1, o espaço amostral colhido pela pesquisa se divide de maneira bem equilibrada entre os três tipos de interesse em filmes nacionais, com uma leve acentuação de pessoas que buscam razoavelmente (36\%). Quando fazemos o cruzamento dessas respostas com base na renda dos respondentes, isso pode nos dar um indício de como esse dado influencia nesse comportamento. Aqui é importante ressaltar que a pesquisa se baseia na renda individual ao invés da renda familiar, como geralmente se faz, porque a nós interessa observar o comportamento individual. As faixas oferecidas como alternativas refletem as categorias da FGV para demarcação de classes sociais ${ }^{2}$. Todas as faixas de renda foram representadas na pesquisa com uma boa margem, refletindo inclusive a pirâmide social brasileira (maioria de pessoas que ganham entre 1 e 4 salários mínimos ${ }^{3}$ e uma minoria que ganha mais de 10 salários).

Gráfico 2 - Gráfico da renda Individual x frequência de busca por filmes nacionais.

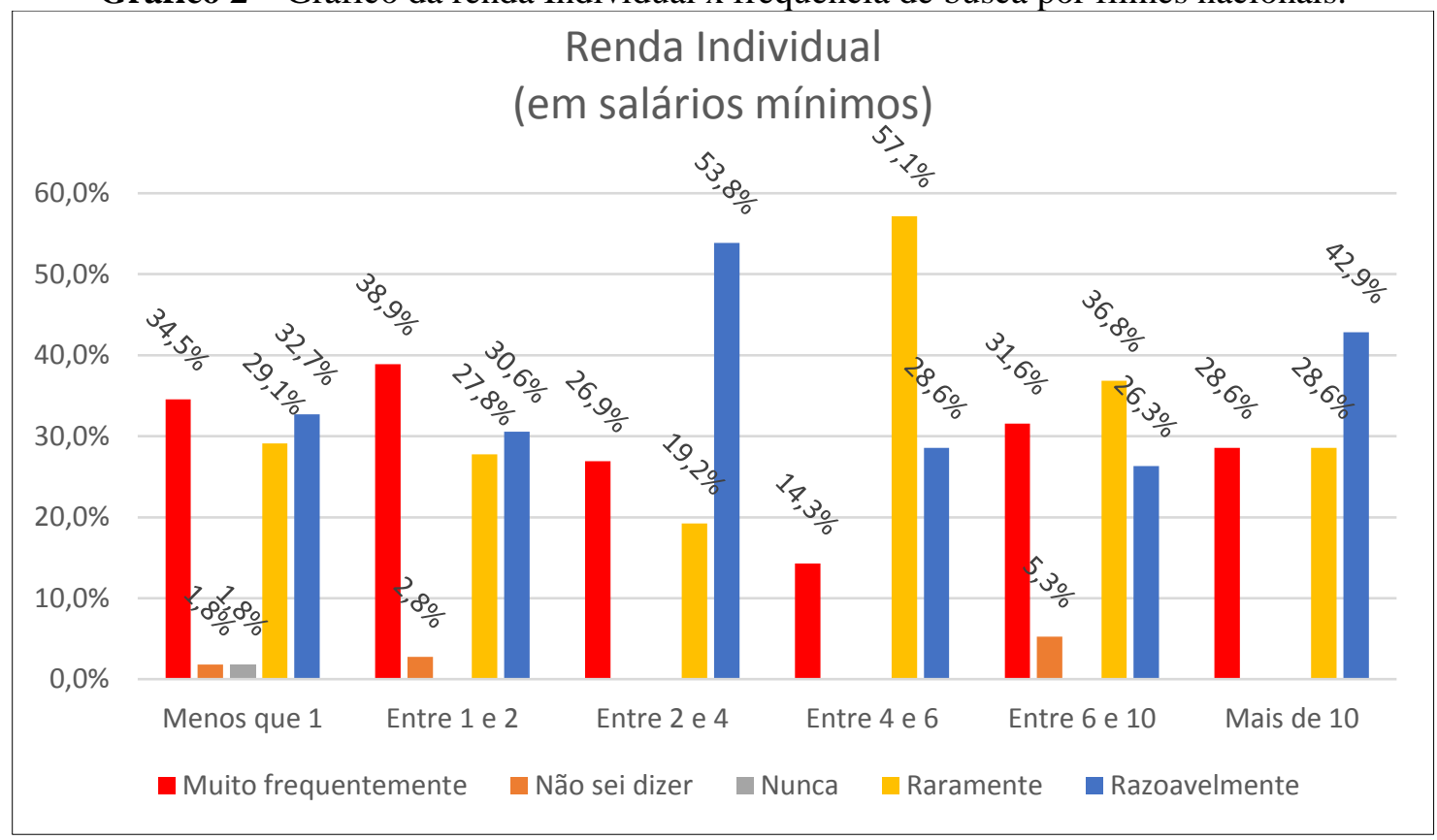

Fonte: Elaboração dos autores.

\footnotetext{
2 O IBGE classifica as classes em: Classe A (quem ganha mais de 20 salários mínimos); Classe B (de 10 a 20 salários mínimos); Classe C (de 4 a 10 salários mínimos); Classe D (de 2 a 4 salários mínimos); Classe E (recebe até 2 salários mínimos). Disponível em: https://invest.exame.com/invest/quiz-qual-sua-verdadeiraclasse-social. Acesso: 15.set.2021

${ }^{3}$ Durante a pesquisa o valor do salário mínimo era de R \$ 1.100,00, de acordo com medida provisória assinada pelo presidente em 30 de dezembro de 2020. Disponível em: https://www.in.gov.br/en/web/dou/-/medidaprovisoria-n-1.021-de-30-de-dezembro-de-2020-297208167. Acesso em 06/2021.
} 
De acordo com as disposições no gráfico acima, observamos que, embora a porcentagem de pessoas que buscam razoavelmente ou muito frequentemente tenda a crescer de acordo com a renda, isso muda quando chegamos na faixa de 4 a 6 salários mínimos, com uma queda de $80,7 \%$ da faixa anterior para $42,9 \%$. A porcentagem volta a crescer nas faixas seguintes de renda, chegando a 71,5\% de pessoas com renda superior a 10 salários mínimos que buscam razoavelmente ou muito frequentemente por filmes nacionais. Isso nos leva a concluir que, embora a renda certamente influencie nesse comportamento, ela não é o fator determinante nesse hábito ou não é o único.

\subsection{A renda versus o gasto com produtos audiovisuais}

Os respondentes também foram questionados sobre seus gastos com produtos audiovisuais, numa média mensal. Podemos ver a disposição das respostas no gráfico seguinte.

Gráfico 3-Gráfico dos gastos mensais com audiovisual.

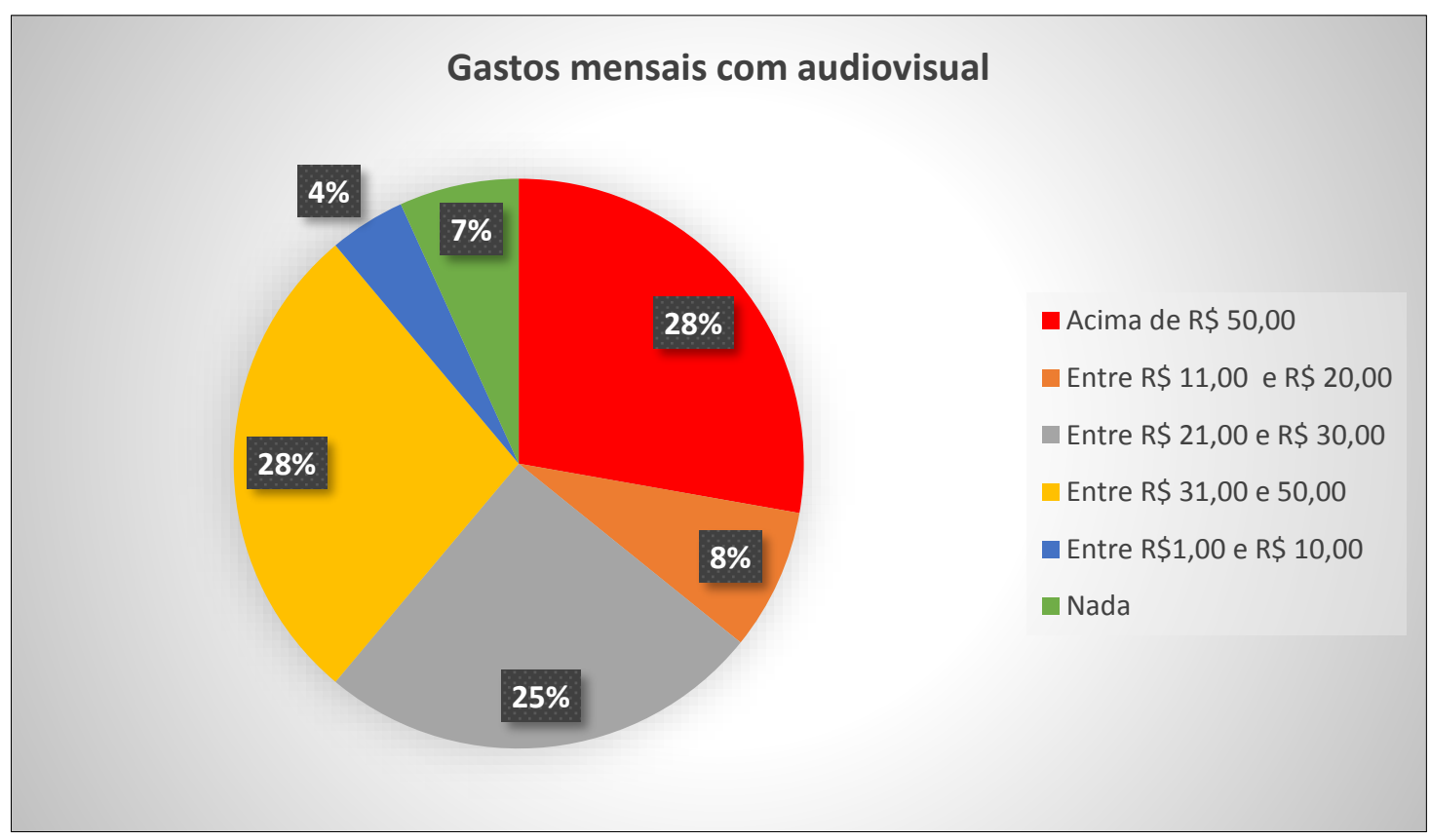

Fonte: Elaboração dos autores. 
O gráfico acima mostra que há um equilíbrio no percentual da amostra entre pessoas que gastam entre $R$ \$ 21,00 e R \$ 30,004; e as faixas logo acima, entre $R$ \$ 31,00 e R \$ 50,00, e ainda acima de $\mathrm{R} \$ 50,00$. As faixas contemplam, em média, o valor de uma ou duas assinaturas mensais de serviços de streaming). As pessoas que gastam menos, embora pouco expressivas na amostra coletada, também aparecem aqui de maneira razoável, de forma que também iremos considerá-las na análise. Novamente, cruzamos esses dados com o recorte de renda dos respondentes, no gráfico a seguir.

Gráfico 4 - Gráfico da renda individual versus o gasto mensal com audiovisual.

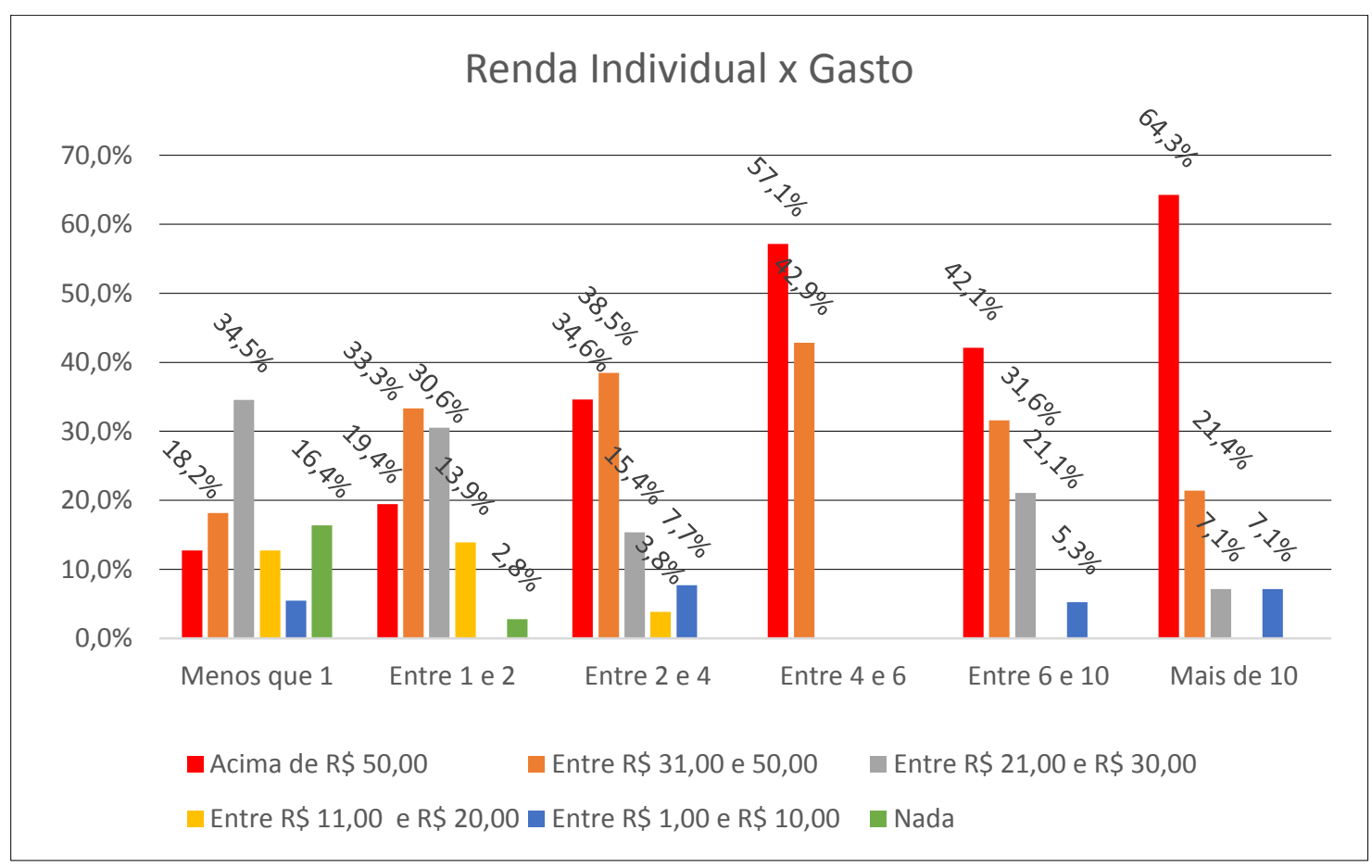

Fonte: Elaboração dos autores.

Vemos aqui que o grupo de pessoas com renda superior a 10 salários mínimos são as que possuem, também, um maior índice de gasto com audiovisual, com 64,3\% afirmando gastar mais de $\mathrm{R} \$ 50,00$ por mês com audiovisual. Também é verdade que, ao passo em que as faixas de renda aumentam, o gasto tende a aumentar.

\footnotetext{
${ }^{4}$ Da data em que o questionário ficou disponível, em 04/2021, as assinaturas mensais dos três serviços mais citados pelos respondentes eram Netflix, por R \$21,90; Amazon Prime por R \$ 9,90; e Globoplay, por R \$19,90.
} 
Entretanto, observa-se também que dentre as pessoas com renda entre 4 e 6 salários mínimos, a disposição a pagar é maior, pois o gasto médio mínimo com audiovisual relatado por todos desse grupo foi entre $\mathrm{R} \$ 31,00$ e $\mathrm{R} \$ 50,00$. Dentre as pessoas com mais de 10 salários mínimos, por exemplo, houve quem relatasse gastar entre $\mathrm{R} \$ 1,00$ e $\mathrm{R} \$ 10,00$. Isso significa que, embora haja uma forte tendência do gasto com produtos audiovisuais aumentar conforme aumenta a renda do brasileiro, isso não é uma verdade absoluta, pois existem também outros fatores que influenciam esse comportamento. A renda, portanto, embora um dado socioeconômico importante que permeia a análise do habitus dos consumidores de cinema nacional, não é por si só suficiente para determinar como esse grupo se comporta nesse campo analisado. Neste sentido, a segunda parte da pesquisa procura investigar, através do grupo focal, outros parâmetros, motivações e argumentos que apontem as origens do consumo audiovisual do brasileiro e sua preferencia por filmes estrangeiros ao invés de filmes nacionais. Os resultados dessa fase serão apresentados oportunamente, após a análise dos resultados encontrados.

\section{Cruzamento de dados com base na área de atuação}

Outro dado importante incluído no questionário foi a ocupação das pessoas. Como a resposta era aberta, por critérios de otimização análise, tivemos que agrupar as categorias em três grandes grupos: Profissionais da economia criativa (artistas, produtores, realizadores, designers, etc.), que somaram 18,6\% do total; Professores e estudantes, por estarem ambos no ambiente acadêmico, que juntos somaram 47,5\% do todo; e o terceiro grupo, que chamaremos aqui de 'profissionais diversos', reunindo as demais respostas, que englobam desde médicos e empresários, a nutricionistas, bancários, funcionários públicos, profissionais liberais, entre outros, que separados não formariam uma parcela percentual significativa, que ficaram juntos por terem atividades profissionais que não envolvem uma relação direta com o capital cultural.

O conceito de capital cultural, como Bourdieu apresenta em seus estudos, tem uma relação direta com o habitus. Bourdieu afirma, por exemplo, que o gosto é uma característica de classe, dizendo que "a disposição estética é (...) uma manifestação do sistema de disposições que produzem os condicionamentos sociais associados a uma classe particular" (BOURDIEU, 1979. p. 59). Entretanto, o autor também argumenta que as classes dominantes são capazes de legitimar sua cultura como a de maior valor simbólico, assim como restringir o acesso às informações sobre 
o que é legítimo. Essa estrutura faz com que as pessoas que tenham de fato acesso a esse conteúdo que é legitimado pelas instituições (universidades, museus, curadores, etc.) como o de maior valor simbólico, assumam um gosto estético diferente de sua classe nos termos de renda (capital financeiro). Em outras palavras, poderíamos imaginar que o autor levanta a ideia de capital cultural também para justificar um "habitus de classe", a capacidade de agentes de uma classe social manifestarem comportamentos de uma classe diferente por terem acesso à informações diferencias, seja a formação acadêmica ou ao consumo cultural em espaços de legitimação dos mesmos (academia, museus, indústria cultural, etc).

Tendo em vista essa ideia de capital cultural, podemos fazer mais alguns cruzamentos para analisar se a relação com o capital cultural das pessoas interfere no hábito de consumo do cinema nacional.

\subsection{Ocupação versus o hábito de ver filmes nacionais}

Quando fazemos novamente o cruzamento do hábito de buscar por filmes nacionais, considerando dessa vez os diferentes recortes de ocupações citados anteriormente, é essa a disposição que temos:

Gráfico 5 - Gráfico profissões versus frequência de busca por filmes nacionais.

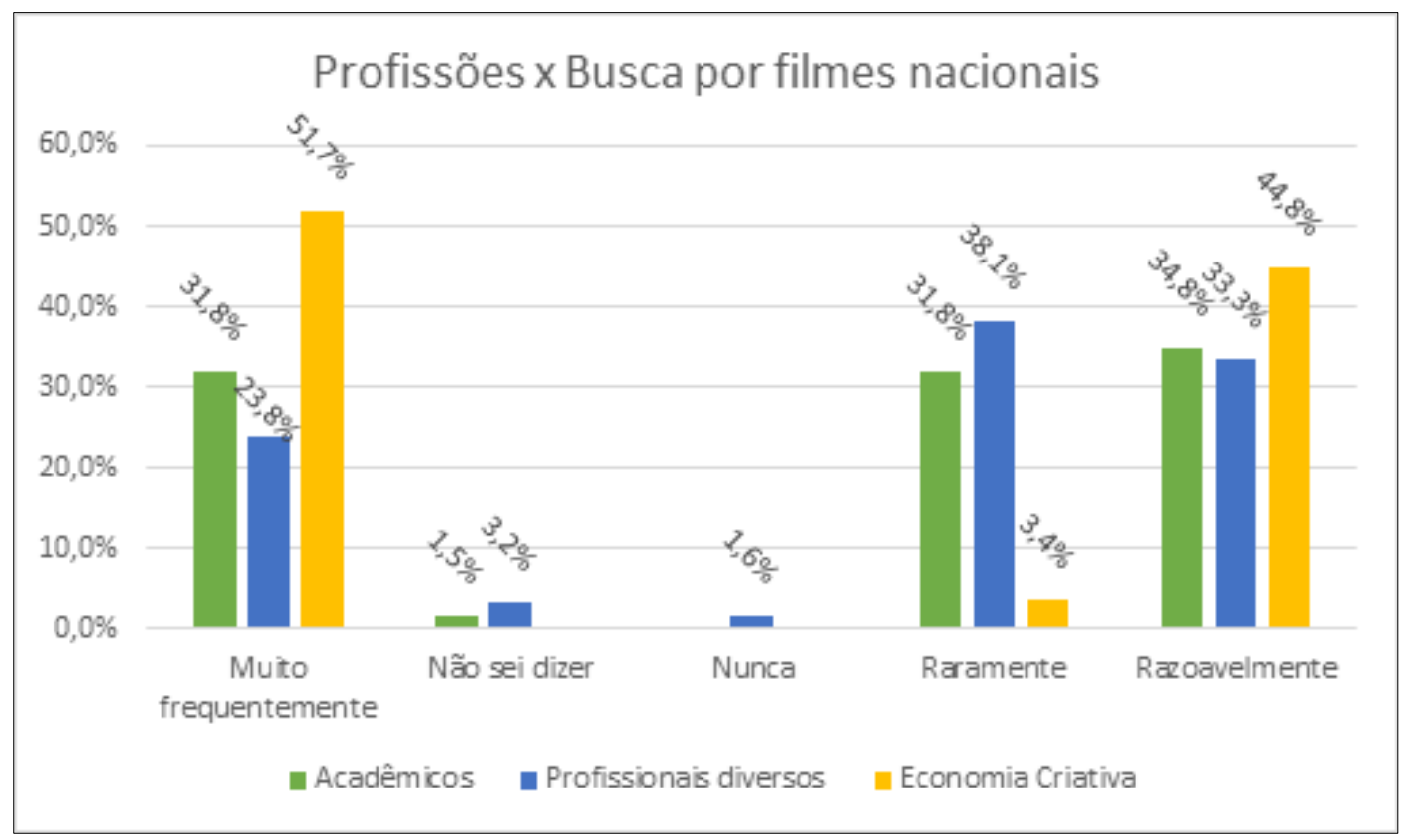

Fonte: Elaboração dos autores. 
A partir dessa disposição é possível perceber que as pessoas que trabalham na chamada economia criativa são as que mais buscam por filmes nacionais $(51,7 \%$ afirmou buscar muito frequentemente por tais filmes), assim como a categoria de profissionais diversos é a que menos apresenta esse hábito $(28,1 \%$ afirmou buscar raramente por cinema nacional). Se somamos ao percentual daqueles que buscam filmes nacionais com frequência razoável, esse grupo soma mais de 95\% do total de respondentes. A categoria que envolve estudantes e professores também apresenta níveis de buscas por filmes nacionais marginalmente acima dos demais, mas abaixo dos níveis dos apresentados por aqueles que compõem o grupo da economia criativa, concentrando-se nas mais nas frequências mais baixas de busca (raramente e razoavelmente). Aqui, percebe-se que, de fato, há uma relação direta entre consumo cultural e meio ou área de atividade, no caso do grupo da economia criativa; mas surpreende quando olhamos para o grupo de estudantes e professores.

\subsection{Escolaridade versus o hábito de ver filmes nacionais}

Outro fator que é importante de ser analisado conjuntamente ao hábito é o grau de escolaridade. Ao fazermos isso com os dados colhidos, observamos, como mostra o gráfico abaixo, que conforme o nível de escolaridade aumenta (da esquerda para a direita no gráfico), também aumenta a porcentagem de pessoas que afirma buscar muito frequentemente por filmes nacionais.

Pós-graduandos e pós-graduados foram os que mais afirmaram buscar muito frequentemente por cinema nacional (40\%), enquanto pessoas com ensino básico foram as que mais afirmaram buscar apenas razoavelmente $(45,5 \%)$. 


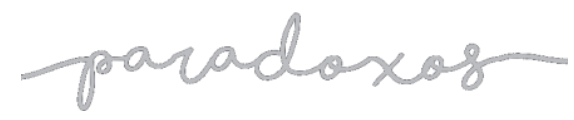

Uma trama em vários atos. Ou o cinema brasileiro em busca de seu público.

Gráfico 6 - Gráfico da escolaridade versus o hábito de ver filmes nacionais.

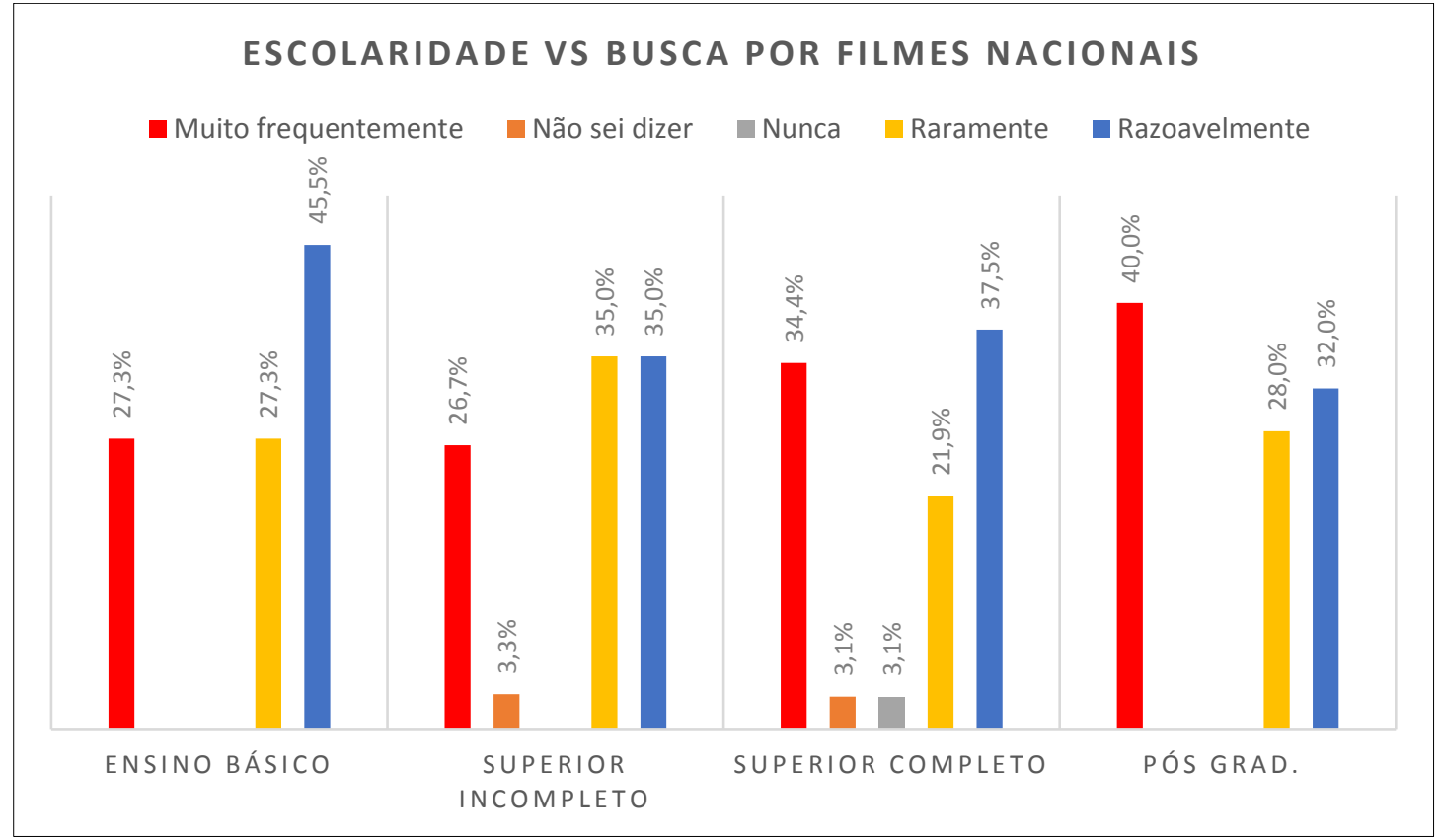

Fonte: Elaboração dos autores.

\section{Conclusões Preliminares}

Sabe-se que tendemos a relacionar maior consumo e disposição a gastar em produtos e serviços a maiores rendas individuais ou familiares. Entretanto, conforme nos alerta Bourdieu (idem), o hábito de consumo cultural (leitura, música, artes, cinema, etc.) relaciona-se diretamente com a formação acadêmica dos indivíduos e se dá a partir de uma relação dialética entre o indivíduo e a estrutura social, ou seja, o habitus.

De acordo com os dados obtidos foi possível perceber que fatores econômicos dispersos como a renda ou classe social, por si só não são capazes de determinar o hábito das pessoas no que se refere ao consumo de cultura e, mais especificamente aqui, o consumo de filmes nacionais. Além disso, como um reflexo dos próprios estudos de Bourdieu, foi possível perceber que uma relação entre o consumo de cinema nacional e o capital cultural existe, uma vez que as pessoas que trabalham com a economia criativa (ou no que Bourdieu trata como campo da indústria cultural) e as que estão no meio acadêmico (campo de produção erudita), apresentam níveis de busca por filmes nacionais maiores que a média das 
outras ocupações reunidas. Comparados os dois primeiros grupos, nos surpreende que haja um montante maior que $50 \%$ de professores e estudantes (considerando-se apenas a ocupação e não o grau de formação) que se concentram entre as faixas de menor frequência de busca/consumo de filmes nacionais.

Além disso, o hábito de ver filmes nacionais também cresce quanto maior é a escolaridade dos brasileiros, o que também atesta para o fato de que o acesso à educação formal tende a ser mais determinante no hábito de consumo de cinema nacional do que fatores econômicos, como a renda ou a classe social.

Com esses resultados preliminares pode-se discutir que ações (de promoção, preço, motivações, aspectos logísticos, entre outros) podem ser empreendidas pelos produtores, distribuidores e exibidores para estimular uma maior busca e consumo de filmes brasileiros, aumentado sua participação no mercado. Esse consumo, entretanto, estará mais fortemente associado a plataformas de streaming e à televisão, posto que apenas 5,1\% dos respondentes afirmam ir à sala de cinema mais de uma vez por semana. Esse aspecto deixa ainda mais claro a necessidade de que os consumidores precisam ser estimulados a buscarem esse conteúdo (uma vez que as plataformas utilizam recursos tecnológicos para apresentar o catálogo de ofertas e que ir ao cinema implica gastos complementares); e ainda a necessidade de uma regulação específica para o filme brasileiro na TV aberta (atualmente só a TV de acesso condicionado tem obrigação de exibição de filmes nacionais independentes, v. Lei 12.485/11), que tem cobertura ampla e irrestrita em território nacional.

\section{Referências Bibliográficas}

BOURDIEU, Pierre. Economia das Trocas Simbólicas. São Paulo: Perspectiva, 2007.

BOURDIEU, Pierre. La distinction: critique sociale du jugement. Paris: Minuit, 1979. DOI: https://doi.org/10.1007/978-3-476-05728-0_9723-1.

ANCINE. Agência Nacional do Cinema. OCA - Observatório Brasileiro do Cinema e do Audiovisual. Ancine. Disponível em: https://oca.ancine.gov.br/. Acesso em: 09 abr. 2018.

ANDREW, J. Dudley. 2002. As Principais Teorias do Cinema. Rio de Janeiro: Ed. Jorge Zahar. 
BENJAMIN, Walter. 2012. A Obra de Arte na Época de Sua Reprodutibilidade Técnica. Porto Alegre: Ed. Zouk.

BRDE - Banco Regional de Desenvolvimento do Extremo Sul. Disponível: http://www.brde.com.br/fsa/o-que-e-fsa/fontes-de-receita/. Acesso em: 09 abr. 2018.

COSTA, Mannuela. Cinema, ao fim e ao cabo. Primeiras impressões sobre o impacto da Lei 12.485/2011, a Lei da TV paga, no Brasil. In: REBECA-Revista Brasileira de Estudos de Cinema e Audiovisual. Ano 4. Ed. 7. Jan-junho, 2015. pp. 356-380. DOI: https://doi.org/10.22475/rebeca.v4n1.176.

COSTA, Mannuela. Cinema Brasileiro Independente no contexto contemporâneo: entre a ficção e a realidade. Rio de Janeiro, UFRJ / EC / PPCC, 2017. 261p.

EISENSTEIN, Sergei M. 2002. A forma do filme. Rio de Janeiro: Ed. Jorge Zahar.

HOLANDA, S. B. de. Raízes do Brasil. Rio de Janeiro: José Olympio,1999.

IKEDA, Marcelo. IKEDA, Marcelo. Cinema brasileiro a partir da retomada - aspectos econômicos e políticos. São Paulo: Summus, 2015. 268p.

MARK, M.; PEARSON, C.S. O Herói e o Fora-da-Lei: como construir marcas extraordinárias usando o poder dos arquétipos. São Paulo: Cultrix, 2001.

REIS, Ana Carla Fonseca. 2007. Economia da Cultura e Desenvolvimento Sustentável. São Paulo: Ed. Manole.

REIS, Ana Carla Fonseca. Economia da Cultura e Desenvolvimento Sustentável. Barueri, Sp: Manole, 2007.

SARAVIA, Enrique. Avaliação de políticas públicas: engenharia reversa dos sistemas de decisão política? Rio de Janeiro, UFRJ / IE / PPED, 2013, mimeo.

SILVA, Hadija Chalupe da. 2010. O filme nas telas: a distribuição do cinema nacional. São Paulo: Ed. Ecofalante.

THROSBY, David. The Economics of Cultural Policy. Cambridge: Combridge University Press, 2010.

THROSBY, David. Economics and Culture. Cambridge: Combridge University Press, 2001.

TOLILA, Paul. Cultura e Economia. Problemas, hipóteses e pistas. Trad.: Celso M. Paciornik. São Paulo: Iluminuras: Itaú Cultural, 2007. 